ORIGINAL ARTICLE

\title{
A survey of current practices in the diagnosis of and interventions for inhalational injuries in Canadian burn centres
}

\author{
Justin K Yeung MD¹, Leslie Tze Fung Leung MD², Anthony Papp MD PhD FRCSC 3
}

\begin{abstract}
JK Yeung, LTF Leung, A Papp. A survey of current practices in the diagnosis of and interventions for inhalational injuries in Canadian burn centres. Can J Plast Surg 2013;21(4):221-225.
\end{abstract}

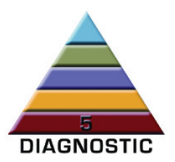

OBJECTIVE: To summarize current Canadian practice patterns in the diagnosis of and interventions for inhalation injuries (INHI).

METHODS: A 10-question survey regarding the diagnosis of and interventions for INHI was sent to the medical directors of all 16 burn centres across Canada.

RESULTS: The response rate to the survey was $50 \%$. Fibreoptic bronchoscopy is required for the diagnosis of INHI in only four centres (50\%). The departments of intensive care, plastic surgery, otolaryngology and respirology are involved in performing fibreoptic bronchoscopy in $87.5 \%, 37.5 \%$, $12.5 \%$ and $12.5 \%$ of Canadian burn centres, respectively. Intubation for INHI is most often based on physical examination results $(87.5 \%)$ and clinical history $(75 \%)$. The most common physical features believed to be most consistent with INHI are dyspnea (87.5\%) and hoarseness $(87.5 \%)$. Common treatments include intubation $(87.5 \%)$, routine ventilatory support $(87.5 \%)$ and chest physiotherapy $(75 \%)$. None of the centres used nebulized heparin. A total of five centres $(62.5 \%)$ routinely changed the fluid resuscitation protocol when INHI was diagnosed. Only two centres (25\%) routinely used prophylactic antibiotics for INHI.

CONCLUSION: Prospective, multicentre trials are needed to generate evidence-based consensus in the areas of diagnosis, grading and treatment for INHI in Canada.

Key Words: Burn; Canada; Inhalational injury; Survey

Inhalation injury (INHI) is a comorbid factor that increases the risk 1 of mortality in burn victims (1-3). The combination of INHI and burn is associated with complex pathophysiological alterations including increased pulmonary microvascular permeability and prolonged cardiac depression in ovine models $(4,5)$. In a Canadian study, Tredget et al (6) reported that INHI increases burn mortality and prolongs hospital stay independent of age and burn size. In spite of the clinical significance of INHI, there has been a lack of academic progress in the clinical management in this field.

Palmieri (7) concluded from the 2007 Inhalation Injury Consensus Conference that questions regarding INHI diagnosis and grading have remained unanswered even though they were initially identified more than two decades previously. Although fibreoptic bronchoscopy is the widely accepted standard to diagnose INHI, other modalities, such as patient history and physical examination, carboxyhemoglobin levels, Xenon-133 scans and pulmonary function tests are used in various nonstandardized combinations (8). There is also insufficient evidence to establish long-term outcomes and treatment protocols in INHI. The use of heparin nebulization, mode of ventilation, timing of intubation and fluid resuscitation requirements are mostly driven by local preferences in individual burn centres.

The controversies in the areas of INHI highlight the need for standardized protocols in both diagnosing and treating INHIs. However, the first step is to evaluate current practices. The challenge is that

\author{
Un sondage des pratiques actuelles sur le diagnostic \\ et les interventions relatifs aux lésions par \\ inhalation dans les centres de brûlés du Canada
}

\begin{abstract}
OBJECTIF : Résumer les profils de pratique actuels quant au diagnostic et aux interventions relatifs aux lésions par inhalation (LINH).

MÉTHODOLOGIE : Les directeurs médicaux des 16 centres de brûlés du Canada ont reçu un sondage de dix questions sur le diagnostic et les interventions relatifs aux LINH.

RÉSULTATS : Le taux de réponse au sondage s'élevait à $50 \%$. La bronchoscopie par fibres optiques est obligatoire dans seulement quatre centres pour diagnostiquer les LINH (50\%). Les départements de soins intensifs, de chirurgie plastique, d'otorhinolaryngologie et de pneumologie participent à la bronchoscopie par fibres optiques dans $87,5 \%, 37,5 \%, 12,5 \%$ et $12,5 \%$ des centres de brûlés du Canada, respectivement. L'intubation découlant de LINH dépend surtout des résultats de l'examen médical (87,5\%) et des antécédents cliniques (75\%). La dyspnée $(87,5 \%)$ et la raucité $(87,5 \%)$ sont les principales caractéristiques cliniques perçues comme les plus évocatrices de LINH. Les traitements fréquents incluent l'intubation ( $87,5 \%)$, le soutien ventilatoire systématique $(87,5 \%)$ et la physiothérapie pulmonaire $(75 \%)$. Aucun des centres ne faisait appel à la nébulisation d'héparine. Au total, cinq centres $(62,5 \%)$ changeaient systématiquement le protocole de réanimation liquidienne au diagnostic de LINH. Seulement deux centres $(25 \%)$ utilisaient systématiquement des antibiotiques en prophylaxie dans ce contexte.
\end{abstract}

CONCLUSION : Il faudra mener des essais rétrospectifs multicentriques pour parvenir à un consensus fondé sur des données probantes au sujet du diagnostic, du classement et du traitement des LINH au Canada.

most Canadian burn centres do not have a sufficient volume of burn patients to support substantial scientific studies. Therefore, the issue should be approached on a national level. There are no studies that have compiled current practices in North America. The objective of the present study was to summarize current Canadian practice patterns in the diagnosis of and interventions for INHI.

\section{METHODS}

The authors designed a 10-question survey (Appendix A) regarding the diagnosis and interventions of INHI. After receiving approval from the University of British Columbia Institutional Review Board (Vancouver, British Columbia), the authors sent the survey to the medical directors of all 16 burn centres across Canada. Following verification of contact information of the burn centres by telephone, an invitation letter was sent electronically; the surveys were then sent in July 2009 by e-mail. A repeat batch of surveys were e-mailed and mailed at two weeks to remind burn centre directors of the option to participate. If no response was received at this time, the authors assumed decline of participation. Returned surveys represented consent to participate in the study. Completed surveys were collected by the principle investigator via fax or e-mail. Individual respondent identifiers were then removed after the data were collected. All results were recorded as provided and compiled using a spreadsheet (Excel, Microsoft Corporation, USA).

\footnotetext{
${ }^{1}$ Department of Plastic Surgery, University of Calgary, Calgary, Alberta; ${ }^{2}$ Department of Plastic Surgery, University of British Columbia;

${ }^{3}$ BC Professional Firefighters' Burn Unit, Vancouver General Hospital, Vancouver, British Columbia

Correspondence: Dr Justin K Yeung, Foothills Medical Centre, Room 382, 1403 - 29 Street Northwest, Calgary, Alberta T2N $4 J 8$.

Telephone 403-944-4317, fax 403-944-2840, e-mail justin.yeung@albertahealthservices.ca
} 


\section{TABLE 1}

Demographics of the respondent Canadian burn centres

\begin{tabular}{|c|c|c|c|}
\hline Centre & $\begin{array}{c}\text { Patients } \\
\text { per year, } \mathrm{n}\end{array}$ & $\begin{array}{c}\text { Inhalation injuries } \\
\text { per year, } n\end{array}$ & Centre director(s) \\
\hline 1 & $101-125$ & $10-20$ & Plastic surgeon \\
\hline 2 & $>125$ & $>20$ & $\begin{array}{l}\text { General surgeon, } \\
\text { Plastic surgeon }\end{array}$ \\
\hline 3 & $>125$ & $5-10$ & $\begin{array}{l}\text { Intensive care unit, } \\
\text { Plastic surgeon }\end{array}$ \\
\hline 4 & $76-100$ & $10-20$ & Plastic surgeon \\
\hline 5 & $>125$ & $>20$ & $\begin{array}{l}\text { Pediatric surgeon, } \\
\text { Plastic surgeon }\end{array}$ \\
\hline 6 & $>125$ & $0-5$ & $\begin{array}{l}\text { Intensive care unit, } \\
\text { Plastic surgeon }\end{array}$ \\
\hline 7 & $0-25$ & $0-5$ & Plastic surgeon \\
\hline 8 & $76-100$ & $0-5$ & $\begin{array}{l}\text { General surgeon, } \\
\text { Plastic surgeon }\end{array}$ \\
\hline
\end{tabular}

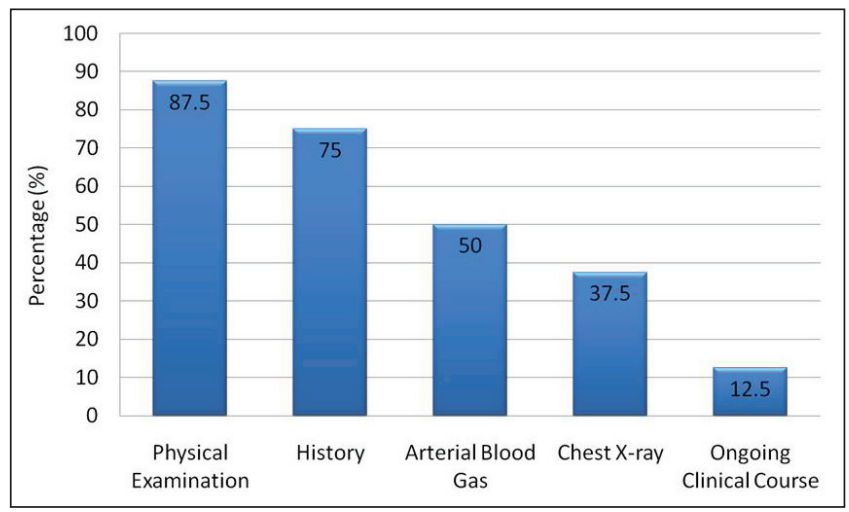

Figure 1) Criteria guiding intubation for inhalation injuries in Canadian burn centres

\section{RESULTS}

\section{Demographics}

Overall, eight of 16 (50\%) Canadian burn centres responded to the survey. The demographics of the respondents are presented in Table 1 . The respondents represented the largest burn centres in Canada. The mean number of patients in the respondent burn centres was 106 patients per year. One-half of the respondents were large centres with $>125$ patients per year. All but one burn centre had a formal burn protocol. All centres had a plastic surgeon involved as the director.

\section{Bronchoscopic diagnosis of INHI}

Fibreoptic bronchoscopy was required for the diagnosis of INHI in only four (50\%) burn centres. The intensive care unit was involved in performing fibreoptic bronchoscopy in seven centres (87.5\%), and the departments of otolaryngology and respirology were involved in one centre $(12.5 \%)$, respectively. A total of three centres $(37.5 \%)$ involved the department of plastic surgery in performing the procedure; however, only one $(12.5 \%)$ relied solely on plastic surgery. Staff physicians performed bronchoscopy in all eight burn centres (100\%) whereas residents were involved in three $(37.5 \%)$ and Fellows were involved in two $(12.5 \%)$.

\section{Clinical diagnosis of INHI}

Intubation for INHI was most oftern based on physical examination results $(87.5 \%)$ and clinical history (75\%) (Figure 1). The top three physical examination features believed to be most consistent with INHI were dyspnea (87.5\%), hoarseness $(87.5 \%)$ and carbonaceous sputum $(75 \%)$ (Figure 2).

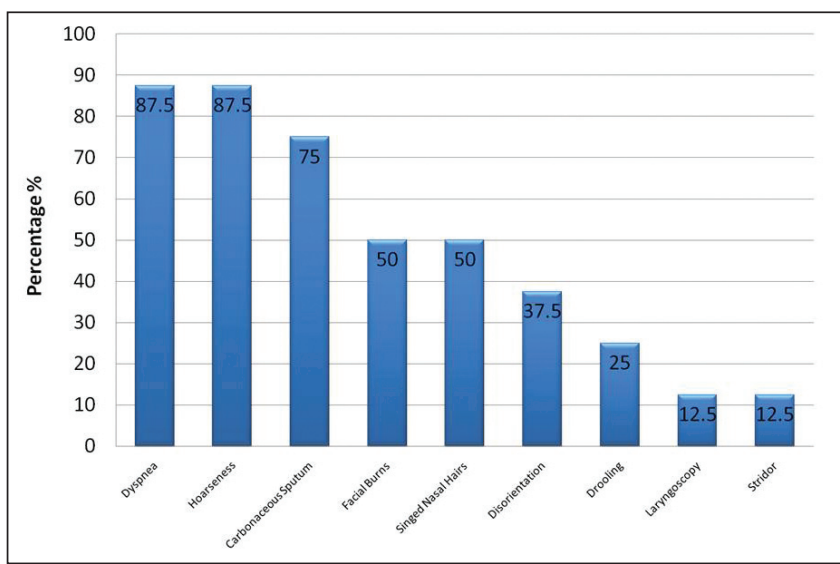

Figure 2) Physical examination findings guiding intubation for inhalation injuries in Canadian burn centres

\section{Treatment of INHI}

The most common treatments for INHI were intubation (87.5\%), ventilator support $(87.5 \%)$ and chest physiotherapy (75\%); no centre routinely used nebulized heparin to treat INHI (Figure 3). A total of five centres $(62.5 \%)$ routinely changed the fluid resuscitation protocol when INHI was diagnosed (Figure 4).

\section{Antibiotic prophylaxis}

Only seven of eight centres (87.5\%) responded to the question of whether antibiotic prophylaxis was used for the diagnosis of INHI. Of the seven respondent centres, two $(28.5 \%)$ routinely used antibiotic prophylaxis in patients with comorbidities; one centre $(14.3 \%)$ responded 'not usually' and the rest $(57.1 \%)$ have never considered using antibiotic prophylaxis in the management of INHI (Figure 5).

\section{DISCUSSION}

The proper early diagnosis of INHI is of great clinical importance because INHI significantly increases morbidity and mortality in burn patients. Many studies support the value of fibreoptic bronchoscopy in diagnosing INHI. In a prospective study involving 130 patients (9), fibreoptic bronchoscopy was found to be more reliable than circumstance of the injury, clinical findings and complementary tests in early diagnoses of INHI, with $94 \%$ specificity and $79 \%$ sensitivity compared with histological findings. In fact, sensitivity may improve when fibreoptic bronchoscopy is repeated in $24 \mathrm{~h}$ to $48 \mathrm{~h}$ in patients with hypovolemic shock $(8,10)$. Using a self-devised bronchoscopic grading system, several authors concluded that fibreoptic bronchoscopy was a useful tool in predicting acute lung injuries and overall survival $(9,11,12)$. On the other hand, Bingham et al (13) concluded that their devised bronchoscopic index was not a good predictor of the level of respiratory support or the duration of intubation in burn patients. Although there are no evidence-based protocols guiding the diagnosis and grading of INHI, it was startling to observe that bronchoscopy - the widely accepted standard of INHI diagnosis that was first used 35 years ago (10) - was only used in $50 \%$ of the surveyed Canadian burn centres.

Despite being the specialists in burn surgery and management in Canada, plastic surgeons are only reported to perform fibreoptic bronchoscopy alone in $12.5 \%$ of the surveyed burn centres. In addition, it is significant that only $37.5 \%$ of the burn centres involve plastic surgery residents in performing the procedure. The increased involvement of plastic surgery and residents in Canadian burn care could explain why bronchoscopy is only used $50 \%$ of the time for diagnosis.

Our survey showed that physical examination findings and clinical history were the top criteria guiding the diagnosis of INHI in Canada. History of injury in a closed space, facial burns, large burn sizes or advanced age should increase the clinician's suspicion in diagnosing INHI (1). Although these modalities cannot ensure diagnostic certainty, they are routinely used in Canada because of their noninvasive 


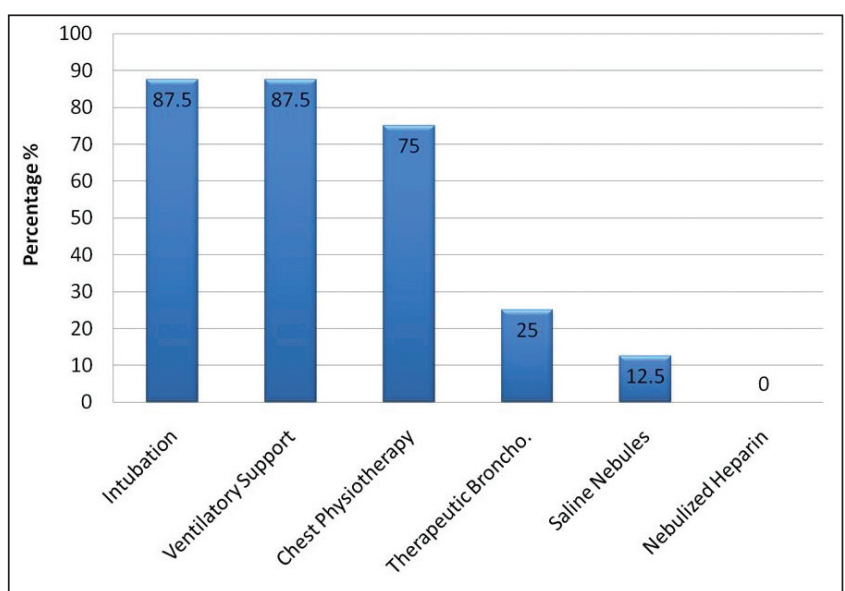

Figure 3) Treatment for inhalation injuries in Canadian burn centres. Broncho Bronchoscopy

nature. The top three symptoms guiding most of Canada's diagnoses of INHI were dyspnea, hoarseness and carbonaceous sputum. Nevertheless, in a retrospective review of 805 patients with INHI, Clark et al (14) reported that dyspnea, hoarseness and carbonaceous sputum were only present in $3 \%, 19 \%$ and $48 \%$ of the patients, respectively. Using only clinical signs to diagnose INHI is nonspecific and may explain the decrease in the trend of reported INHI-associated mortality due to the potential of overestimation from a misdiagnosis. Therefore, the use of a combination of findings appears to be more reliable in predicting INHI (15). This, however, is still insufficient to validate the lack of fibreoptic bronchoscopy use in some Canadian burn centres. On the other hand, there is no consensus to proceed with which diagnostic modality or combination if the burn patient does not exhibit any suspicious physical findings. Some Canadian burn centres use arterial blood gas and chest $\mathrm{x}$-ray to guide INHI diagnosis; however, due to low sensitivity, these were shown to be poor predictors of respiratory failure and death (16).

In the treatment of INHI, the majority of Canadian burn centres consistently focus on supportive therapy: intubation, ventilatory support and chest physiotherapy. None of the centres currently uses routine inhalational medications in treating INHI. Preliminary evidence supporting of the use of $\beta_{2}$-agonists and tocopherol in INHI exists in animal models and small, single-centre, retrospective studies $(17,18)$. However, with the lack of confirmation from prospective, multicentre clinical trials, their effectiveness and safety remain inconclusive. Another pharmacological option that has created controversy is the combination of nebulized heparin and $\mathrm{N}$-acetylcystine. In a retrospective study, Desai et al (19) showed that this combination reduced mortality, atelectasis and reintubation rates in pediatric patients with INHI. However, a more recent retrospective study by Holt et al (20) showed no difference in pulmonary findings or mortality in adult patients treated with this combination. The evidence for nebulized heparin and $\mathrm{N}$-acetylcystine is split, but it is interesting to note that this combination is not used at all in Canada.

In the present study, $63 \%$ of all Canadian burn centres routinely changed the fluid resuscitation protocol when INHI was diagnosed because the evidence in support of an ideal protocol for patients with INHI is weak. Burn patients with INHI generally have increased fluid requirements $(21,22)$; however, they are also at risk of complications from fluid overload, such as compartment syndrome, acute respiratory distress syndrome, multiple organ failure and death (23). Due to the complexity of pathophysiology in burn patients, especially those with concomitant INHI, it is challenging to elicit a predictable fluid response without an accurate fluid formula, appropriate monitoring parameters and measurable end points that are supported by substantial evidence.

The use of antibiotic prophylaxis upon diagnosis of INHI is a nonevidence-based practice observed in some Canadian burn centres.

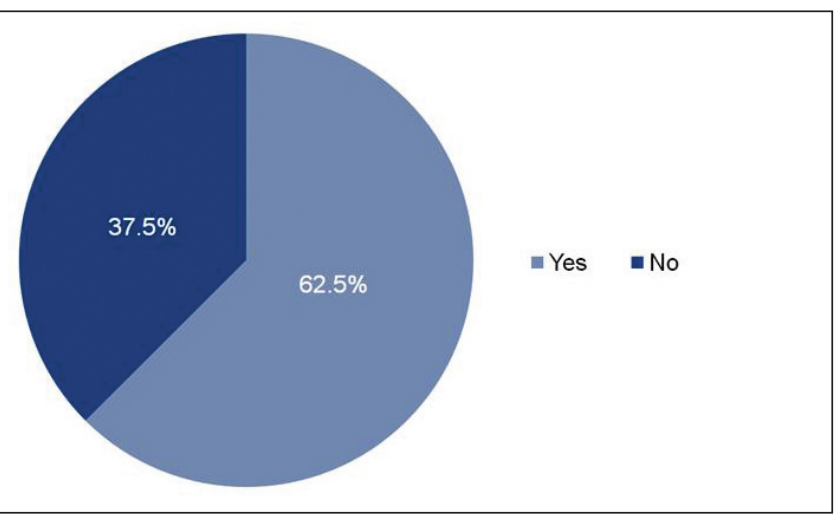

Figure 4) Proportion of Canadian burn centres that change their fluid resuscitation protocol when inhalation injury is diagnosed

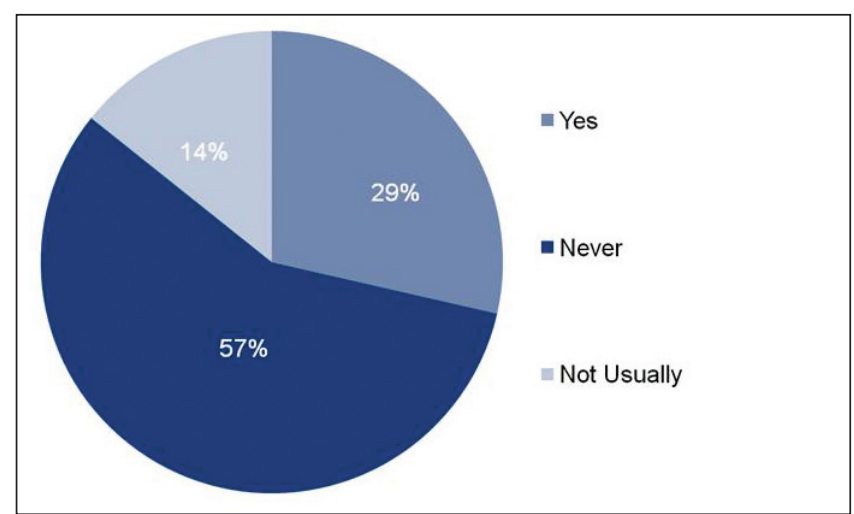

Figure 5) Proportion of Canadian burn centres that use antibiotic prophylaxis when inhalation injury is diagnosed

There is currently no evidence to recommend the use of antibiotic prophylaxis in preventing infections in patients with INHI. In fact, in a prospective study, Levine et al (24) reported no differences in mortality, pulmonary and septic complications in patients with INHI treated with gentamicin versus placebo. It was unexpected to learn that only four of seven Canadian burn centres (57\%) never used antibiotic prophylaxis in INHI.

There were several limitations to the present study. First, the low response rate $(50 \%)$ raises concerns about the significance of the data. However, most of the data were represented by the largest burn centres in Canada and, therefore, the data obtained are important and valuable. Second, the answers to the survey were solely based on the burn directors' expert opinion in current burn management in their area; the perspectives from other integral members of the burn team were not represented. On a similar note, because most of the centre directors were plastic surgeons, their views regarding the management of INHI may be biased and different from other departments such as the intensive care unit or the emergency department.

Despite its shortcomings, the present study was the first in Canada to provide a nationwide perspective of the clinical management of INHI. The present study highlights the challenges in burn care with the paucity of evidence. The only other nationwide survey investigating the management of INHI was conducted by Prior et al (25) in the United Kingdom. The authors reported that $81 \%$ of the burn units in the United Kingdom require fibreoptic bronchoscopy to diagnose INHI, and no unit uses a purely clinical diagnosis; $76 \%$ of the units use nebulizing medications in treating INHI. From these findings, it is apparent that the management of INHI is inconsistent between the burn centres in the United Kingdom and Canada. With the lack of evidence-based guidelines, most practices regarding the management of INHI are governed by local custom of the individual burn centres. 
Evidence-based recommendations regarding the interventions for INHI relies on standardizing diagnosis (7). Research efforts must be focused on the reproducible grading of INHI using bronchoscopy. Recognizing that clinical history and physical findings may be insufficient to define INHI, several authors have used objective grading scales to assess the severity of INHI via bronchoscopy $(11,26,27)$. Mosier et al (26) showed that higher abbreviated injury scores were associated with earlier onset of acute respiratory distress syndrome, longer intensive care unit stay and higher incidence of multiple organ dysfunction syndrome $(11,26)$. One limitation of the present study was that it was a small retrospective cohort. Ikonomidis et al (27) used a different grading system that subcategorized bronchoscopic findings into upper airway and lower tracheobronchial tree to show that lower extension of injury is associated with prolonged mechanical ventilation. This was a single-centre study lacking external validation.

The current challenge is the absence of a uniform grading system that has been shown to reliably predict the clinical course of burn patients with INHI. We encourage joint efforts from the Canadian burn centres to prospectively evaluate a single bronchoscopic grading system in predicting clinical outcomes.

\section{CONCLUSION}

Physical examination is the most common tool used in the diagnosis of INHI in Canada. Although fibreoptic bronchoscopy is the gold standard, it is only used $50 \%$ of the time for diagnosis. Interventions for INHI are fairly consistent across the nation, with the focus on supportive treatment without the use of nebulizing agents. Prospective, multicentre trials are needed to generate evidence-based consensus in the areas of diagnosis, grading and treatment of INHI in Canada.

\section{APPENDIX A}

\author{
A Survey of Current Practices in Diagnosis and Interventions of \\ Inhalation Injuries in Canadian Burn Centres \\ 1. How many burn patients does your unit treat annually \\ (inpatients)? \\ $\square 0-25$ \\ $\square$ 26-50 \\ $\square$ ㄴ $1-75$ \\ $\square 76-100$ \\ $\square$ 101-125 \\ $\square>125$
}

2. Your burn centre is run by:

$\square$ A general surgeon

$\square$ A pediatric surgeon

$\square$ A plastic surgeon

$\square$ Other $\rightarrow$ Please clarify:

3. How many inhalation injuries do you treat per annum (mean last 5 years)?

$\square 0-5$

$\square 5-10$

$\square$ 10-20

$\square>20$

4. Does your centre require use of bronchoscopy for confirmation of inhalation injury?

$\square$ Yes

$\square$ No

5. If no, what criteria are used for indication for intubation for inhalation injury? (Please check one or more options that apply)

$\square$ History

$\square$ Physical exam (Please answer question 4 if this box is checked)

$\square$ Arterial blood gas

$\square$ Chest X-ray

$\square$ Perfusion Ventilation Scan

$\square$ Pulmonary Function Test

$\square$ Other $\rightarrow$ Please comment:
6. What physical exam finding usually indicates intubation of a burn patient at your institution? (Please check one or more options that apply)
$\square$ Hoarseness
$\square$ Singed nasal hairs
$\square$ Facial burns
$\square$ Shortness of breath
$\square$ Drooling
$\square$ Dyspnea
$\square$ Disorientation
$\square$ Other $\rightarrow$ Please comment:

7. Who primarily performs bronchoscopy at your centre when

indicated?

$\square$ Staff

$\square$ Fellow

$\square$ Resident

And of what department are they from?

$\square$ ICU

$\square$ Respirology

$\square$ Plastic Surgery

8. Do you have a routine for treating inhalation injuries?

(Please check one or more options that apply)

$\square$ Intubation

$\square$ Routine ventilatory support (e.g. oxygen and bronchodilators)

$\square$ Nebulized heparin

$\square$ Therapeutic bronchoscopy

$\square$ Chest physiotherapy

$\square$ Other $\rightarrow$ Please comment:

9. Do you routinely change the fluid resuscitation protocol when

inhalation injury is diagnosed?

$\square$ Yes

$\square$ No

10.Do you use antibiotic prophylaxis for inhalation injuries?

$\square$ Yes, always

$\square$ Yes, if other co-morbidities are present

(e.g. Diabetes mellitus, alcoholism, other)

$\square$ Yes, other indication $\rightarrow$ Please comment:

$\square$ Never

This survey was completed by at the burn unit.

\section{REFERENCES}

1. Shirani KZ, Pruitt BA Jr, Mason AD Jr. The influence of inhalation injury and pneumonia on burn mortality. Ann Surg 1987;205:82-7.

2. Edelman DA, White MT, Tyburski JG, Wilson RF. Factors affecting prognosis of inhalation injury. J Burn Care Res 2006;27:848-53.

3. Ryan CM, Schoenfeld DA, Thorpe WP, Sheridan RL, Cassem EH, Tompkins RG. Objective estimates of the probability of death from burn injuries. N Engl J Med 1998;338:362-6.

4. Traber DL, Herndon DN, Stein MD, Traber LD, Flynn JT, Niehaus GD. The pulmonary lesion of smoke inhalation in an ovine model. Circ Shock 1986;18:311-23.

5. Soejima K, Schmalstieg FC, Sakurai H, Traber LD, Traber DL. Pathophysiological analysis of combined burn and smoke inhalation injuries in sheep. Am J Physiol Lung Cell Mol Physiol 2001;280:1233-41.

6. Tredget EE, Shankowsky HA, Taerum TV, Moysa GL, Alton JD. The role of inhalation injury in burn trauma. A Canadian experience. Ann Surg 1990;212:720-7.

7. Palmieri TL. Inhalation injury consensus conference: Conclusions. J Burn Care Res 2009;30:209-10.

8. Cancio LC. Airway management and smoke inhalation injury in the burn patient. Clin Plast Surg 2009;36:555-67.

9. Masanes MJ, Legendre C, Lioret N, Maillard D, Saizy R, Lebeau B. Fiberoptic bronchoscopy for the early diagnosis of subglottal inhalation injury: Comparative value in the assessment of prognosis. J Trauma 1994;36:59-67.

10. Hunt JL, Agee RN, Pruitt BA Jr. Fiberoptic bronchoscopy in acute inhalation injury. J Trauma 1975;15:641-9.

11. Endorf FW, Gamelli RL. Inhalation injury, pulmonary perturbations, and fluid resuscitation. J Burn Care Res 2007;28:80-3. 
12. Chou SH, Lin SD, Chuang HY, Cheng YJ, Kao EL, Huang MF. Fiber-optic bronchoscopic classification of inhalation injury: Prediction of acute lung injury. Surg Endosc 2004;18:1377-9.

13. Bingham HG, Gallagher TJ, Powell MD. Early bronchoscopy as a predictor of ventilatory support for burned patients. J Trauma 1987;27:1286-8.

14. Clark WR, Bonaventura M, Myers W. Smoke inhalation and airway management at a regional burn unit: 1974-1983. Part I: Diagnosis and consequences of smoke inhalation. J Burn Care Rehabil 1989;10:52-62

15. Marek K, Piotr W, Stanislaw S, et al. Fibreoptic bronchoscopy in routine clinical practice in confirming the diagnosis and treatment of inhalation burns. Burns 2007;33:554-60.

16. Blinn DL, Slater H, Goldfarb IW. Inhalation injury with burns: A lethal combination. J Emerg Med 1988;6:471-3.

17. Palmieri TL. Use of beta-agonists in inhalation injury. J Burn Care Res 2009;30:156-9.

18. Traber DL, Traber MG, Enkhbaatar P, Herndon DN. Tocopherol as treatment for lung injury associated with burn and smoke inhalation. J Burn Care Res 2009;30:164-5.

19. Desai MH, Mlcak R, Richardson J, Nichols R, Herndon DN. Reduction in mortality in pediatric patients with inhalation injury with aerosolized heparin/ $\mathrm{N}$-acetylcystine [correction of acetylcystine] therapy. J Burn Care Rehabil 1998;19:210-2.
20. Holt J, Saffle JR, Morris SE, Cochran A. Use of inhaled heparin/ $\mathrm{N}$-acetylcystine in inhalation injury: Does it help? J Burn Care Res 2008;29:192-5.

21. Navar PD, Saffle JR, Warden GD. Effect of inhalation injury on fluid resuscitation requirements after thermal injury. Am J Surg 1985;150:716-20.

22. Cancio LC, Chavez S, Alvarado-Ortega M, et al. Predicting increased fluid requirements during the resuscitation of thermally injured patients. J Trauma 2004;56:404-13.

23. Klein MB, Hayden D, Elson C, et al. The association between fluid administration and outcome following major burn: A multicenter study. Ann Surg 2007;245:622-8.

24. Levine BA, Petroff PA, Slade CL, Pruitt BA Jr. Prospective trials of dexamethasone and aerosolized gentamicin in the treatment of inhalation injury in the burned patient. J Trauma 1978;18:188-93.

25. Prior K, Nordman G, Sim K, Mahoney P, Thomas R. Management of inhalational injuries in UK burns centres - a questionnaire survey. J Intensive Care Society 2009;10:141-4.

26. Mosier MJ, Pham TN, Park DR, Simmons J, Klein MB, Gibran NS. Predictive value of bronchoscopy in assessing the severity of inhalation injury. J Burn Care Res 2012;33:65-73.

27. Ikonomidis C, Lang F, Radu, A, Berger M. Standardizing the diagnosis of inhalation injury using a descriptive score based on mucosal injury criteria. Burn 2012;38:513-9. 